Journal of Money and Economy

Vol. 16, No. 1, Winter 2021

pp. 93-114

DOI: $10.29252 /$ jme.16.1.93

Original Research Article

\title{
Stress Testing of Credit Risk in the Iranian Banking System
}

Mahboobeh Sanatkhani"

Received: 26 Sep 2020
Fatemeh Bazzazan ${ }^{\dagger}$

Approved: 10 Jan 2022

Economic crisis imposes extensive losses on banks and credit institutions, thereby increasing their credit risk and dissolution. The macroeconomic conditions are the major cause of financial stress, the destructive effects of which can greatly be reduced by accurate risk management in the banking system. This study aims to examine stress testing in the Iranian banking system by using Iranian banks' data from 2008 to 2017 . The results in the panel VAR framework and Monte Carlo simulation by using macroeconomic variables and credit risk show that the Iranian banking system is mostly affected by the scenarios of long-term shock in the country's macroeconomic factors. In other words, changes in one period of the variables have a minimum effect on credit risk. However, a three-period horizon of interest rate and the inflation rate has the maximum effect. In contrast, economic growth has the minimum effect on the degree of default in Iranian banks.

Keywords: Credit Risk, Stress Test, Banking System.

JEL Classification: E58, G21, G28

\section{Introduction}

The banking industry is the most important sector of the financial system of any country. It enjoys a special status in developed and developing economies due to the intermediation operations between depositors and facility seekers, financing investment projects, and strong connections to different economic sectors.

\footnotetext{
* Department of Economics, Faculty of Social Sciences and Economics, Alzahra University, Tehran, Iran; mahboobsanatkhani@gmail.com

$\dagger$ Department of Economics, Faculty of Social Sciences and Economics, Alzahra University, Tehran, Iran; fbazzazan@alzahra.ac.ir (Corresponding Author).
} 
An examination of the status of banking sector in the Iranian financial market shows that the volume of its assets from the total value of the country's financial market is about $73 \%$, indicating the large size of the banking sector in Iran's economy. Moreover, the banking system's share of the country's domestic finances is more than $91 \%$, suggesting that the Iranian economy is bank-centered or bank-based. On the other hand, due to this profession's nature and its specific features, and due to giving different loans, the banking sector is always faced with instability and risks such as lack of repayment by loan, i.e., credit risk. Therefore, accurate management of credit risk is necessary for any banking system, and a major tool for credit risk management is stress testing. This test alerts bank managers and bank supervisors about the unexpected and negative outcomes of some risks.

In recent decades, numerous financial stress events have occurred around the world. Based on the study by Lindgren et al. (1996) about two-thirds of the International Monetary Fund members have had many banking issues that have led to stress. Iran's economy and banking system are no exemption, and the odds of stress are high for them. Due to the key role of bank stability and health in Iran's economic stability, one cannot attend to bank risk management without considering stress testing.

Based on various studies, there are different definitions of stress. Some regard stress as a situation in which there is instability. Stability refers to a state in which the allocation of resources in the system is efficient; the existing risks are properly identified, measured, and managed; and forecasts are made to have sufficient flexibility for coping with shocks and agitations (Jahangard \& Abdeshah, 2017). Specifically, in financial systems, and especially in banks in which intermediation of funds is a major operation, if the resources (deposits) are efficiently allocated to facility seekers and economic projects, the resulting risks (credit risk, market risk, liquidity risk, etc.) are identified and managed, and there are savings and capital for coping with shocks, one can claim that there is some degree of stability in them. Still, if any of these stages is not properly followed, the system will encounter problems or, in a limited state, stress.

On the other hand, a country's general economic conditions play a major role in the banks' adoption of internal policies in giving loans. If the economic conditions are estimated to be stable, banks expect that the probability of loans' default should be reduced; therefore, they have a higher tendency to paying credit and funding investment projects. Therefore, macroeconomic variables such as the value of the gross domestic product (GDP), unemployment, inflation rate, and exchange rate are among the factors 
determining banks' risks and behaviors in terms of credits. Credit institutions should consider the country's economic condition in terms of prosperity for paying the volume of facilities and the probability of default of facility seekers and giving loans accordingly. For instance, inflation and an increased price index are indices of a country's economic instability that deteriorate households' income state, affect their loan payment, and cause banks' problems. A change in GDP is another factor influencing loan repayment ability, and this problem for banks and credit institutions translates to credit risk.

With respect to the relationship between the performance of the banking system and the economic variables explained in the above examples, any shock or stress imposed on the country's economic condition disrupts banking activities. One can conclude that macroeconomic conditions play a pivotal role in the banking system. To establish stability, prevent stress, and prepare for stress, the banking sector around which most economic transactions and investment projects revolve should be well prepared. Based on the literature and the guidelines proposed by The Basel Committee on Banking Supervision, the International Monetary Fund, the Bank for International Settlements, etc., the most important and accessible tool for this purpose is performing stress testing, which is an essential step to take.

In this study, considering the importance of non-performing loans in the balance sheets of banks and credit institutions, which is also one of the important indicators of credit risk, we decided to perform the stress test for the country's credit risk banking network in different scenarios.

Stress testing has received little attention from Iranian studies due to the obstacles to data collection. Moreover, in the few existing articles, the data on non-current claims of banks and credit institutions have been used generally. However, in this study, the data of non-current claims are used as divided by different economic sectors. To this end, given that vulnerability of different economic sectors, including agriculture, industry and mining, housing and construction, trade, services, etc., to macroeconomic shocks in the repayment of loans and concessional facilities are different, the stress test was performed separately for these sectors. In this study, the model presented by Wilson, $(1997 \mathrm{a}, \mathrm{b})$ was used to measure the effect of macroeconomic shocks on the probability of non-repayment of credits by different economic sectors. Therefore, the effect of macroeconomic shocks on borrowers' credit quality was first investigated, and the model proposed by Sorge and Virolainen (2006) was employed to correlate the default rate macroeconomic factors. After specifying the model, the way the default rate changes due to macroeconomic 
shocks overtime was simulated, allowing access to estimates of nonperforming loans to determine the credit portfolio in different macroeconomic conditions. In this case, the banking system's potential credit losses against the risk-taking capacities ${ }^{1}$ of the system can be calculated.

In this study, we examined the macroeconomic indicators such as GDP growth and inflation, and interest rates to perform the stress test following Sorge and Virolainen (2006), and predict future values of the above variables in different scenarios. Moreover, in the studies conducted on stress testing, the autoregressive (AR) method has been used to predict macroeconomic variables. In this study, due to the analysis of different economic sectors separately, it was attempted to make this prediction by the panel VAR model. After estimating the models' parameters and error components, the credit risk behavior (non-performing loan ratio or default rate) for each economic sector was simulated in the baseline scenario ${ }^{2}$ to perform the stress test using nonparametric methods such as the Monte Carlo simulation. In the next step, the default rate distribution was simulated in different scenarios.

The present paper was organized into five sections. The second section presents the review of the literature. The third section provides the theoretical foundations of the stress test. The fourth section deals with the analysis of the results, and finally, in the fifth section, the results are presented.

\section{Review of Literature}

In recent decades, many studies have been conducted on macro stress testing and its experimental application, some of the most important of which are mentioned in this section.

Wilson (1997a, b) presented a model in which the sensitivity of default rate probabilities in different economic sectors is directly correlated with macroeconomic variables. This model is used to simulate the default rate trend over time by creating macroeconomic shocks to the system. It is possible to estimate the expected and unexpected credit losses according to the macroeconomic conditions.

Merton (1974) proposed a model in which different financial institutions are first valued, and then changes in the value of assets affect the probability of default. This approach requires significant information.

\footnotetext{
${ }^{1}$ Banks' capital is used as a measure to assess the banking system's vulnerability to various shocks over time.

${ }^{2}$ This is a scenario in which there is no shock.
} 
Boss (2002) used Wilson's (1997) model for Austrian banks' macro stress testing. He defined the default probabilities of all provided facilities as a function of macroeconomic variables.

Jokivuolle et al. (2008) proposed a stress testing framework for minimum capital requirements in which credit risk was modeled with macroeconomic variables. They defined scenarios such as mild shocks and considered the improvement in credit risk, and, consequently, estimated the necessary changes in the minimum capital. They also emphasized the importance of stress testing of the minimum capital requirements for the future along with credit losses.

In their method, Shijaku, H. and Ceca, K. (2010) used the existing stress testing methods for the credit risk of the whole system and adapted it to Albanian financial intermediaries' data and features. Their model begins with the VAR equation system, which considers the common behavior of financial and real variables. This equation is modeled to include some dynamics for longer shock duration over a period of default rate. Then, they defined the shock to non-financial variables (growth rate, interest rate, exchange rate, etc.) and similarly computed the range of the default rate in the crisis scenario.

When the stress test uses macro scenarios for the banking sector, it is implicitly assumed that macro variables are useful for predicting banks' performance. Guerrieri and Welch (2012) examined whether the variables that projected loans, incomes and capital in the U.S. bank holding companies' stress testing were better than the models they did not consider. Using general bank performance data, they found that macro factors played a beneficial role.

In their paper, Melecky and Padpiera (2012) reviewed and compared the stress testing practices of central banks in Central and Southwestern Europe and provided an overview of the challenges facing the stress test in the future. They focused on these banks for making a comparison and designed baseline and stress scenarios. By correlating macroeconomic scenarios, microeconomic factors, and risk characteristics, they computed risk exposure based on risk indicators and estimated the outcome indicators to inform macroprudential policies.

Lu and Yang (2012) introduced a stress-testing model with a dummy variable that refers to non-performing loans of Agricultural Banks of China. The results showed that the decrease in GDP growth, the decrease in the general price level, the decrease in the nominal money supply, and the increase in housing prices increase non-performing loans. From a long-term perspective, commercial banks need to set up an internal system to reduce macro variables' effects. 
Buncic and Melecky (2013) propose a new practical approach to macroprudential stress testing. Their study shows there is a higher correlation between the probability of default and the loss given default during stress periods; a negative effect of lending concentration and residual loan maturity on unexpected losses; and the use of an economic risk-weighted capital adequacy ratio as the relevant outcome indicator to measure the resilience of banks to materializing credit risk. The authors apply the proposed approach to a set of Eastern European banks and discuss the results.

Mohammed and Onour (2019) investigated the link between default loans and macroeconomic to assess Islamic banks' exposure to credit risks and then design stress testing scenarios to assess the banking system's resilience to adverse shocks. The results suggest that the credit risk exposure of Islamic banks in Sudan is mainly affected by bank-specific variables, which include changes in total assets, total deposits, and total loans; all of them have a negative and significant impact on the probability of default loans. The study also indicates that the macroeconomic variables, which include domestic product growth, change in exchange rate premium, and change in money supply, have positive but insignificant effects on the risk of default loans. The study concludes by pointing out that Sudan's Islamic banking system is more vulnerable to bank-specific risk exposure than macroeconomic indicators. Stress testing has not been much addressed in domestic studies. However, many studies have been conducted on the effect of economic variables or macroeconomic instability on some banking indicators.

Using the generalized method of moments (GMM), Noroozi (2014) determined the factors affecting the country's banks' credit risk in the period 2006-2012. The results showed that banks' credit risk is affected by macroeconomic variables, and in particular, the real interest rate, inflation rate, government debt, and unemployment rate are positively correlated, and GDP growth is negatively correlated with banks' credit risk. Besides, banking characteristics such as bank size and profitability have negative effects, and the credit risk of the previous period positively affects banks' credit risk.

In their study, Kafaie and Rahzani (2017) investigated the effect of macroeconomic factors on Iranian banks' liquidity risk using a regression framework with quarterly panel data and information obtained from 14 banks from the first quarter of 2006 to the fourth quarter of 2013. The model estimation results using the dynamic ordinary least squares method showed that macroeconomic factors and selected banking characteristics all affect banks' liquidity risk. 
In their study, Jahangard and Abdolshah (2017) investigated the effect of macroeconomic variables on bank stability using data from 17 banks during the period 2007-2012. The results indicated that the inflation rate had a significant negative effect on the studied period's banking stability index. The interest rate had a significant positive effect, and the GDP growth had a significant negative effect on banks' stability. They also measured the Herfindahl-Hirschman index to analyze the effect of centralized banking on the stability index, which had a positive effect; however, it was not significant.

Abdolshah and Moshiri (2017) performed the stress testing of default probabilities in the Iranian banking industry using the credit portfolio approach. They used systematic equation and simulation methods to estimate the effect of economic variables on default rates. Then, they employed the VAR model to estimate the dynamic relationships of macroeconomic variables. The results showed that the unemployment rate shock was the most destructive factor for default rates, and the second strongest shock to the default rate was the exchange rate shock. The GDP growth rate shock also had a significant impact. Inflation rate shock had the least effect.

\section{Model and Methodology}

In this study, the macro model of the probability of default was designed for different economic sectors based on the study of Sorge and Virolainen (2006) and Jokivuolle et al. (2008), who used Wilson's (1997a, b) model to analyze default rates correlated with macroeconomic factors.

In this model, the average default rate (non-performing loan ratio) for sector $j$ is obtained by dividing non-performing loans (past-due loans, overdue debts, and doubtful debts) to the total facilities taken in that sector. Initially, the default rate for industry $\mathrm{j}$ is defined as the following logistic function:

$P D_{j, t, x}=\frac{1}{1+\exp \left(y_{j, t, x}\right)}$

Where $P D_{j, t, x}$ is the probability of default for industry $\mathrm{j}$ at time $\mathrm{t}$, and $y_{j t, x}$ is an industry-specific indicator of the variables $X$ (i.e., economic growth, interest, and inflation rates), in which the following equation estimates the parameters:

$y_{j, t, x}=\beta_{j, 0}+\beta_{j, 1} X_{1, t, s}+\beta_{j, 2} X_{2, t, s}+\cdots+\beta_{j, n} X_{n, t, s}+\vartheta_{j, t, s}$

Higher values of $y_{j, t, x}$ indicate a better state of the economy with a lower probability of default. It is the stage of modeling and estimating 
macroeconomic variables that show the health status of the economy. In this study, instead of the AR(p) model, which was used by Jokivuolle et al. (2008) to predict macroeconomic variables, the panel VAR model was used to consider the interactions between macroeconomic variables in different sectors.

It is noteworthy that in this study, according to the study conducted by Sorge and Virolainen (2006), the variables of GDP growth rate, inflation rate, and interest rate were selected as macroeconomic indicators. By applying the changes made in the model, the modeling of different economic variables is as follows:

$x_{j i t}=\mu_{j i}+\pi_{j i 1} x_{j i t-1}+\pi_{j i 2} x_{j i t-2}+\cdots+\pi_{j i p} x_{j i t-p}+\varepsilon_{j i t}$

Where i represents macroeconomic variables and credit risk index, and $\mathrm{j}$ represents different economic sectors, $\mu_{\mathrm{j} i}=\left(\mu_{\mathrm{j} 1} \cdot \mu_{\mathrm{j} 2} \ldots . \mu_{\mathrm{jk}}\right)$ are constant coefficients of equations in each economic sector, $x_{j i t}=\left(x_{j 1 t} \cdot x_{j 2 t} \cdot \ldots . x_{j k t}\right)$ is the vector of explanatory macroeconomic factors and credit risk index, and $\varepsilon_{\mathrm{jit}}=\left(\varepsilon_{\mathrm{j} 1 \mathrm{t}} \cdot \varepsilon_{\mathrm{j} 2 \mathrm{t}} \cdot \ldots \cdot \varepsilon_{\mathrm{jkt}}\right)$ is the vector of error components of equations.

The matrix of regression coefficients with $\mathrm{k}$, the macroeconomic variable, and $\mathrm{j}$, each economic sector, at each time lag (m represents the time lag) is as follows:

$\pi_{j m}=\left[\begin{array}{cccc}\pi_{11 m} & \pi_{12 m} & \ldots & \pi_{1 k m} \\ \pi_{21 m} & \pi_{22 m} & \ldots & \pi_{2 k m} \\ \vdots & \vdots & \ldots & \vdots \\ \pi_{k 1 m} & \pi_{k 2 m} & \ldots & \pi_{k k m}\end{array}\right]$

Finally, by estimating the above equations' parameters and the error components, future paths of default rates in different economic sectors are simulated. Using the Monte Carlo method, the default rate distribution can be determined depending on the simulated macro scenarios. At each stage of the simulation, a vector of macroeconomic factors and default rates is obtained.

Misina et al. (2006) described the loss distribution approach in four steps:

1) Create macroeconomic variables using Equation (3).

2) Create a vector $S$ of random variables with the variance-covariance matrix given by $\widehat{\sum}_{\vartheta}$. It is done first by creating a vector $Z \sim N(0, I)$ and then calculating $\vartheta_{t}=A^{\prime} Z_{t}$, in which $\widehat{\Sigma}=A A^{\prime}$.

3) To obtain the default probability values for each industry at a given point in time, substitute the results of the previous two steps into the sector default probability function (2). 
4) For each value of the simulated default probability for the industry, calculate the expected loss in that industry according to the following equation:

$E l_{t}^{S}=P D_{j, t, x} \times e x_{t}^{S} \times l_{t}^{S}$

Where $l_{t}^{S}$ is the default loss value, which is usually considered to be $50 \%$, and $e_{t}^{S}$ is the exposure rate of industry to the banking system, which according to the study of Misina et al. (2006) is equal to the amount of loans received by each industry to the total loans. The total expected loss value is obtained by the sum of expected losses in all industries. The loss distribution can be obtained by simulating the process with the Monte Carlo method (with the desired accuracy).

\section{Analysis of Results}

In this study, quarterly data from 2008 to 2017 on inflation, economic growth, interest rate, and credit risk (non-performing loan ratio or default rate) were collected from the Central Bank. Following the steps of stress testing in the study of Jokivuolle et al. (2008), a programming code was prepared using MATLAB software.

This program consists of 5 steps: the data used for the tests are entered in the first step. The second step involves VAR prediction, which predicts the values of the model's macro variables using the estimated coefficients of the panel VAR model for each sector. The third step involves estimating Equation (3) against the selected macroeconomic variables to obtain the residual coefficients and matrix. The regression residuals in each sector are used to calculate the variance-covariance matrix, which is later converted into a correlation matrix for Cholesky factorization. The Cholesky factorization matrix is then multiplied by a vector of 300,000 values generated by normal distribution to obtain a residual matrix that is used to calculate the probability of default for each sector. Then, 300,000 probabilities of default calculated in each sector are multiplied by the default loss, which is assumed to be $50 \%$, to obtain 300,000 different expected loss values. The total expected loss distribution is obtained by the sum of the losses in each sector. Stress testing shocks in the estimation process are obtained by substituting experimental values with the specified shocks to make VAR predictions. 


\subsection{Estimation of Panel VAR Model of Macroeconomic Variables} According to the Bayesian Panel VAR model, including research variables, the results obtained based on different industries' quarterly data for three equations of economic growth, inflation rate, and interest rate are given in the table below.

Table 1

Estimated coefficients of model lagged variables in different equations

\begin{tabular}{|c|c|c|c|c|c|c|}
\hline & \multicolumn{3}{|c|}{ Building } & \multicolumn{3}{|c|}{ Industry and mining } \\
\hline & GDP growth & Inflation & Interest rate & $\begin{array}{l}\text { GDP } \\
\text { growth }\end{array}$ & Inflation & Interest rate \\
\hline GDP growth (-1) & -0.437 & 0.017 & -0.014 & -0.432 & 0.017 & -0.014 \\
\hline GDP growth (-2) & -0.214 & 0.058 & -0.021 & -0.213 & 0.058 & -0.021 \\
\hline GDP growth (-3) & 0.086 & 0.043 & -0.014 & 0.087 & 0.044 & -0.014 \\
\hline GDP growth (-4) & 0.072 & 0.004 & -0.022 & 0.071 & 0.005 & -0.022 \\
\hline Inflation (-1) & -0.135 & 0.499 & -0.008 & -0.134 & 0.497 & -0.008 \\
\hline Inflation $(-2)$ & 0.030 & -0.205 & 0.074 & 0.030 & -0.205 & 0.075 \\
\hline Inflation (-3) & -0.093 & 0.198 & 0.014 & -0.093 & 0.198 & 0.014 \\
\hline Inflation $(-4)$ & -0.111 & -0.029 & -0.028 & -0.112 & -0.029 & -0.028 \\
\hline Interest rate $(-1)$ & -0.099 & -0.052 & 0.954 & -0.101 & -0.055 & 0.958 \\
\hline Interest rate $(-2)$ & 0.087 & 0.256 & -0.036 & 0.083 & 0.255 & -0.035 \\
\hline Interest rate $(-3)$ & -0.728 & -0.016 & 0.018 & -0.731 & -0.017 & 0.018 \\
\hline Interest rate $(-4)$ & 0.416 & -0.289 & -0.058 & 0.415 & -0.289 & -0.059 \\
\hline \multirow[t]{3}{*}{ constant } & 4.173 & 2.891 & 1.325 & 7.494 & 4.162 & 1.723 \\
\hline & \multicolumn{3}{|c|}{ Agriculture } & \multicolumn{3}{|c|}{ Service } \\
\hline & GDP growth & Inflation & Interest rate & $\begin{array}{l}\text { GDP } \\
\text { growth }\end{array}$ & Inflation & Interest rate \\
\hline GDP growth (-1) & -0.434 & 0.017 & -0.014 & -0.436 & 0.016 & -0.014 \\
\hline GDP growth (-2) & -0.216 & 0.059 & -0.021 & -0.214 & 0.058 & -0.021 \\
\hline GDP growth $(-3)$ & 0.087 & 0.043 & -0.014 & 0.087 & 0.043 & -0.014 \\
\hline GDP growth (-4) & 0.070 & 0.004 & -0.022 & 0.070 & 0.004 & -0.022 \\
\hline Inflation (-1) & -0.135 & 0.499 & -0.008 & -0.135 & 0.499 & -0.008 \\
\hline Inflation $(-2)$ & 0.031 & -0.204 & 0.075 & 0.029 & -0.205 & 0.075 \\
\hline Inflation $(-3)$ & -0.093 & 0.197 & 0.014 & -0.093 & 0.197 & 0.014 \\
\hline Inflation $(-4)$ & -0.112 & -0.029 & -0.028 & -0.112 & -0.029 & -0.028 \\
\hline Interest rate $(-1)$ & -0.088 & -0.058 & 0.956 & -0.087 & -0.054 & 0.956 \\
\hline Interest rate $(-2)$ & 0.086 & 0.252 & -0.035 & 0.088 & 0.257 & -0.036 \\
\hline Interest rate $(-3)$ & -0.729 & -0.016 & 0.018 & -0.727 & -0.017 & 0.018 \\
\hline Interest rate $(-4)$ & 0.416 & -0.288 & -0.059 & 0.416 & -0.289 & -0.059 \\
\hline constant & 7.846 & 3.592 & 1.728 & 6.619 & 3.590 & 1.784 \\
\hline
\end{tabular}

Source: Research Findings

\subsection{Scenario Simulation}

To determine the potential losses in a sudden macroeconomic crisis, an artificial shock can be applied to one of the macroeconomic variables used to explain the sector-specific default rate. The stress test was performed by setting the scenario variable to an initial value and then tracking the effect of shock on the other variables through VAR processes to obtain the realized 
values of the variables in the upcoming $\mathrm{k}$ periods used to calculate the default rate in each sector. Using the Monte Carlo simulation method, the obtained default rate can be used in each sector to simulate the distribution of bank loan portfolio losses under macroeconomic conditions (Misina et al. 2006). This study used the scenario frameworks of Boss (2002) and Virolainen (2004) to determine the shock to GDP, interest rate, and inflation rate in various sectors of the Iranian economy. Shocks are selected to reflect the maximum negative historical movement in each data set. These shocks are large enough that they are considered abnormal but remain acceptable.

Scenario 1: 5\% decline in GDP growth in the next quarter and then natural growth by the panel VAR model

Scenario 2: 5\% decline in GDP growth in the next three quarters and then natural growth by the panel VAR model

Scenario 3: $10 \%$ increase in inflation rate in the next quarter and then natural growth by the panel VAR model

Scenario 4: $10 \%$ increase in inflation rate in the next three quarters and then natural growth by the panel VAR model

Scenario 5: an interest rate of $10 \%$ in the next quarter and then normal growth by the panel VAR model

Scenario 6: an interest rate of $10 \%$ in the next three quarters and then normal growth by the panel VAR model

\subsection{Credit Loss Distribution}

In addition to the baseline scenario in which no shocks are applied to the variables and predictions are made based on the panel VAR model, six macroeconomic shock scenarios were implemented to judge the stability of Iranian sectors' loans to macroeconomic changes environment. Expected and unexpected losses under different scenarios are presented in Table 2. 
Table 2

Expected and unexpected loss values under different scenarios

\begin{tabular}{llll}
\hline & $\begin{array}{l}\text { Mean } \\
\text { (Expected loss) }\end{array}$ & $\begin{array}{l}\text { VaR at 99\% } \\
\text { confidence level } \\
\text { (Unexpected loss) }\end{array}$ & $\begin{array}{l}\text { VaR at 99.9\% } \\
\text { confidence level } \\
\text { (Unexpected loss) }\end{array}$ \\
\hline Baseline scenario & 0.089 & 0.192 & 0.264 \\
Scenario 1 & 0.089 & 0.192 & 0.266 \\
Scenario 2 & 0.092 & 0.195 & 0.267 \\
Scenario 3 & 0.089 & 0.192 & 0.264 \\
Scenario 4 & 0.098 & 0.201 & 0.271 \\
Scenario 5 & 0.089 & 0.192 & 0.267 \\
Scenario 6 & 0.117 & 0.204 & 0.271 \\
\hline
\end{tabular}

Source: Research Findings

Fig. 1 shows the credit loss distribution under the baseline scenario, in which the expected loss value at the level of 0.089 and the unexpected loss value based on the Value at Risk (VaR) at $99 \%$ confidence level are equal to 0.192. Figs. 2 and 3 show the simulated loss distribution in scenarios 1 and 2 for negative shocks to economic growth. Under the proposed scenario, a negative shock to economic growth in one quarter had minor effects on the sectoral loan portfolio, i.e., it was not much different from the projected loss under normal conditions. The results of this simulation showed that short-term shocks to economic growth have a minimal effect on the probability of credit default in Iran's financial sector, and financial institutions expect to have sufficient financial resources to cover such losses. In this case, the expected loss value at the level of 0.089 and the unexpected loss value based on the Value at Risk (VaR) at 99\% confidence level was equal to 0.192. In addition, under the third scenario, the results indicated that negative shocks to the economic growth of different sectors, even if they continue for three quarters, will have a small effect on the expected and unexpected loss distribution, so that expected loss value at 0.092 and unexpected loss value based on the Value at Risk (VaR) at $99 \%$ confidence level were equal to 0.195 , indicating that the expected loss compared to the baseline scenario increased by about 4.3 , which is a small figure. 


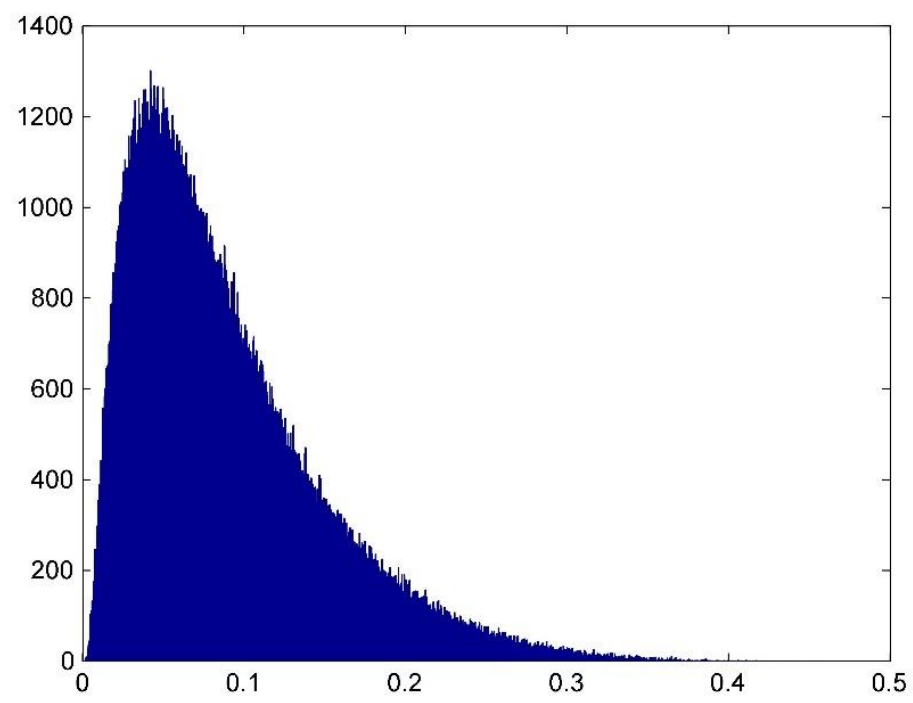

Figure 1. Distribution of the aggregate credit loss under the baseline scenario

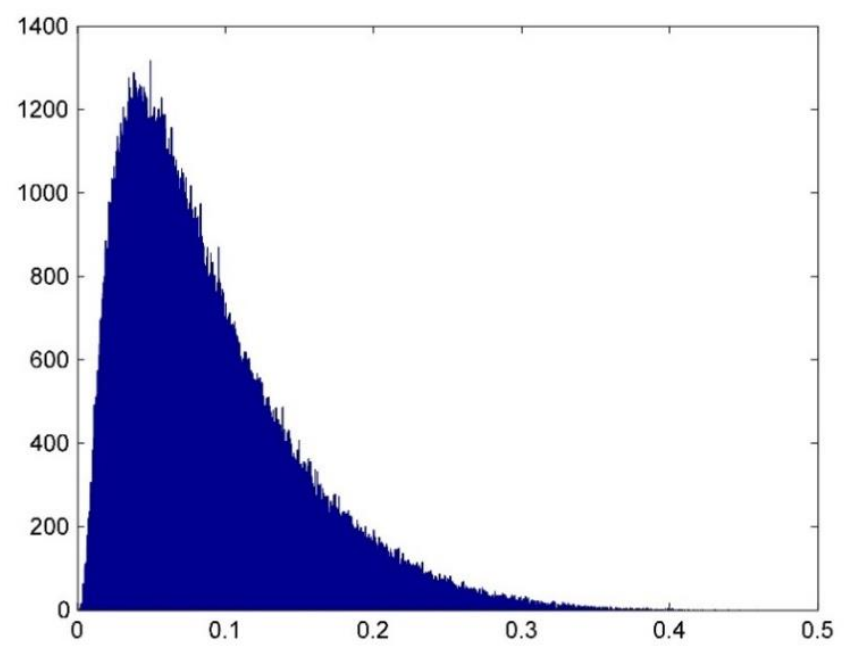

Figure 2. Distribution of the aggregate credit loss under the scenario 1. 


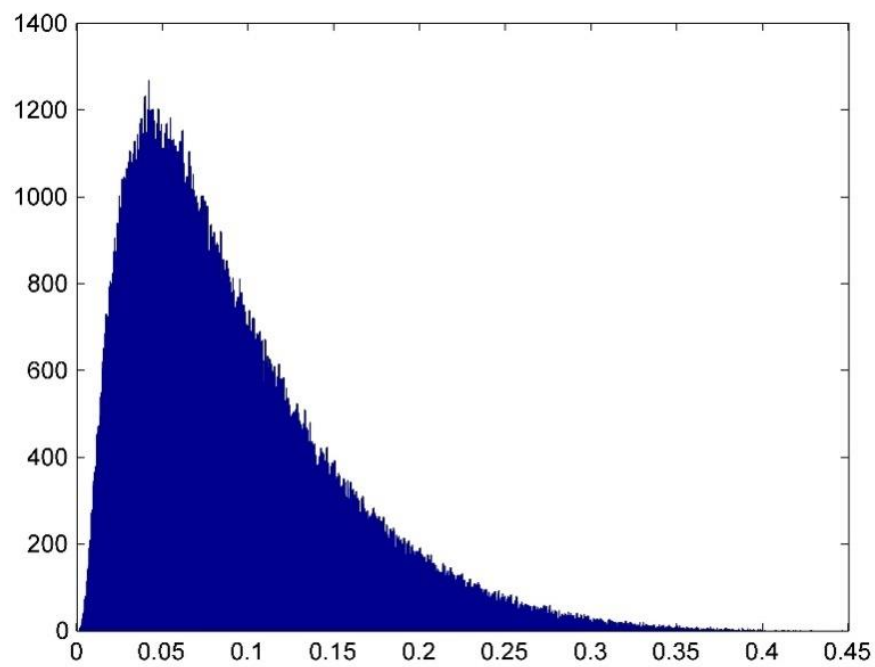

Figure 3. Distribution of the aggregate credit loss under the scenario 2.

Figs. 4 and 5 show the credit loss simulation under rising inflation scenarios 3 and 4 . Based on the shock results, $10 \%$ inflation in a quarter caused the expected loss at the level of 0.089 and the unexpected loss based on the Value at Risk (VaR) at 99\% confidence level to be equal to 0.192 . Hence, the results are slightly different from the baseline scenario. Therefore, increasing inflation in one quarter had a minimal effect on credit losses. However, rising inflation in three quarters showed different results compared to the baseline scenario and the scenarios of increasing economic growth. Unlike the scenario of declining economic growth in three quarters, the probability of credit loss increased by $10 \%$, so that in this case, the expected loss at the level of 0.098 and the unexpected loss based on the Value at Risk (VaR) at 99\% confidence level was equal to 0.201 . 


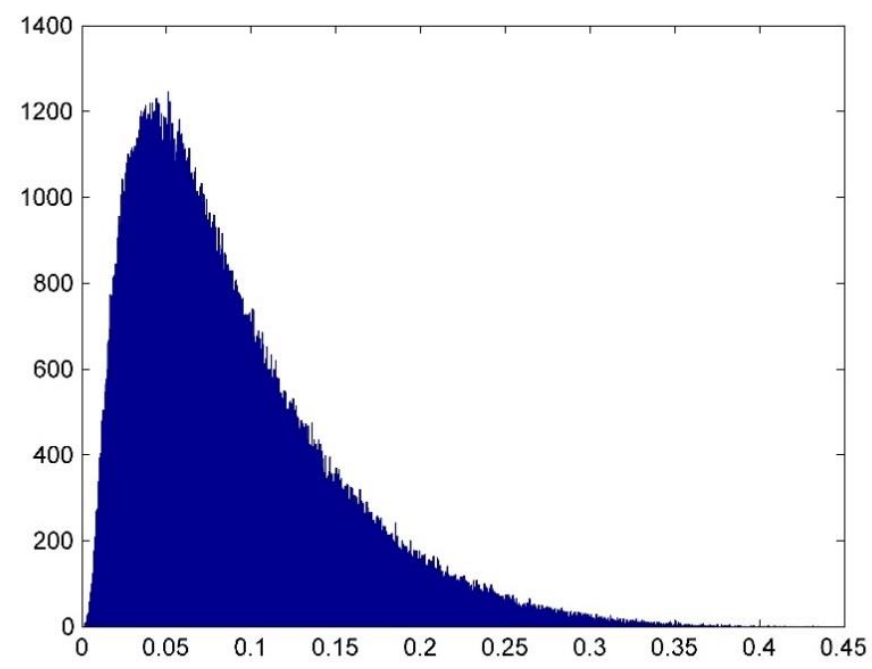

Figure 4. Distribution of the aggregate credit loss under the scenario 3

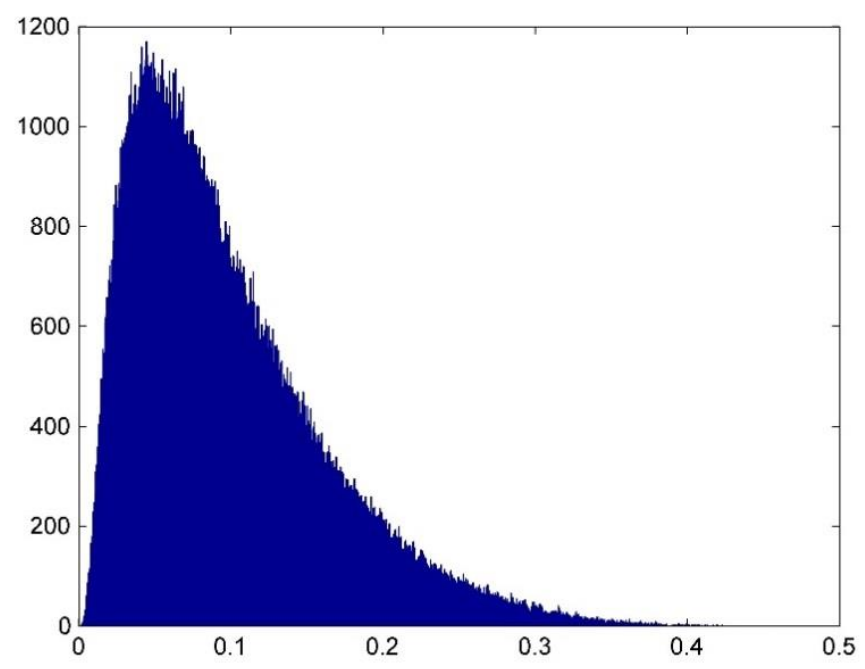

Figure 5. Distribution of the aggregate credit loss under the scenario 4. 
Figs. 6 and 7 show the credit loss simulation under interest rate scenarios 5 and 6 . The results showed that the effect of an interest rate shock in one quarter was small and similar to economic growth and inflation shocks; it had relatively limited consequences. However, low interest rates had strong impacts in three quarters and negatively affected the credit portfolio compared to one-quarter shocks. Overall, in low interest rates for three consecutive quarters, the expected loss was $31 \%$ higher than the one-quarter shock and other studied scenarios. The results showed that with such a scenario, the financial sector might be at risk of having an insufficient capital buffer to hedge such losses. Suppose the financial system is not adjusted to such a reality. In that case, the financial system's stability may be jeopardized in the short term, and the financial sector may not be able to recover from the shock. The maximum value of the portfolio at risk of loss is equal to $20 \%$ at the $99 \%$ confidence level, which is higher than the one-quarter scenario.

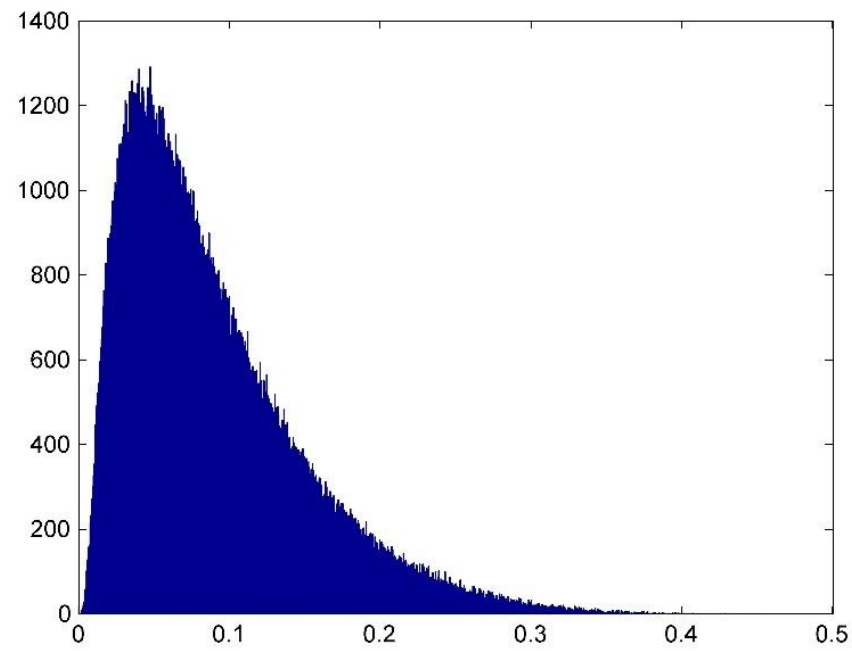

Figure 6. Distribution of the aggregate credit loss under the scenario 5. 


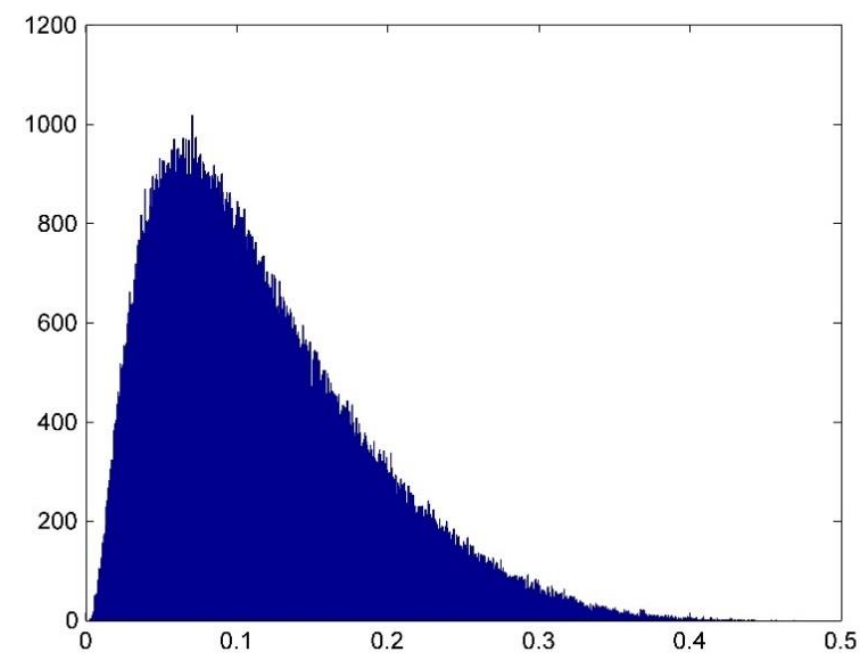

Figure7. Distribution of the aggregate credit loss under the scenario 6.

\section{Conclusion}

Accurate credit risk management is a necessity in every banking system. The most important issue in it is determining the banks' internal policies regarding giving loans and identifying the probabilities of loan default. The most important credit risk management tool is stress testing. The present study attempts to use stress testing on the banking facilities allocated to different economic sectors in Iran in order to evaluate the Iranian banking system's vulnerability to shock in macroeconomic variables.

To this purpose, the stress testing of the financial sector of the Iranian economy was analyzed using quarterly data on macroeconomic indicators such as GDP growth and inflation, and interest rates under various scenarios from 2008 to 2017.

This study evaluates the effect of shocks to macroeconomic variables on the credit quality of loans based on Wilson's (1997) methods. To this end, the relationship between the default rate and macroeconomic variables is examined. After model specification, the change in the default rate distribution due to shocks imposed on the macroeconomic over time is simulated. This process provides access to estimations of non-current claims for determining the credit portfolio in different macroeconomic conditions. In other words, 
macroeconomic scenarios are made under the base and stress scenarios with respect to the shocks imposed on macro variables. The magnitude of the effect of different shocks is calculated by comparing the default probabilities distribution under the base shock scenarios.

After estimating the parameters and error components of the models and predicting the model variables using the panel VAR model, the credit risk behavior (non-performing loan ratio or default rate) was first simulated for each economic sector using the Monte Carlo simulation method, and then, the stress test was performed. This study's findings showed that Iran's financial sector is more affected by interest and inflation rates than the GDP shock. Different scenarios indicated that one-quarter changes in the above variables had a minimal impact on the credit losses of different sectors, while in a threequarter horizon, the interest rate had the highest and economic growth had the least effect on expected and unexpected losses. This result is the same as what Vazquez et al. (2012) did in Brazil, and similar results were achieved in a study on Croatia, in which the authors concluded that rapid growth in loans increased the probability of a rise in credit risk (Kraft and Jankov, 2005). In Latvia, the rapid growth of GDP was possible due to the substantial growth in the loan portfolio, which, paired with insufficient analysis, led to instability and growth in non-performing loans (Fainstein \&Novikov, 2011).

The results of the study suggest that the default rate would become higher if real GDP growth in Hong Kong and the Mainland deteriorated, property prices in Hong Kong declined, and interest rates rose, and vice versa. The coefficient of the lagged default rate yt -2 is positive and significant, so there is positive autocorrelation in default rates, suggesting that a macroeconomic shock can produce a prolonged impact on the default rate. It leads us to analyze the development of the default rate over a time horizon that is longer than the duration of the artificial shock in order to reflect the long-term impact of the stress.

Inflation and increase in the general price index are among the important indicators of instability in the country's economy, which reduce the real value of assets and increase the operating and non-operating expenses of banks. During this period, banks are reluctant to provide facilities due to the devaluation of loans. Simultaneously, with early returns of other markets such as housing, stocks, currency, and gold, the deposit outflow occurs, which again affects banks' lending power. On the other hand, inflation leads to a worsening of household incomes and may affect the repayment of their loans and cause problems for banks. However, as the inflation rate rises, some people benefit by increasing the value of their assets, and the actual cost of 
debt decreases, and accordingly, the probability of default may decrease. The present study results indicated that the negative effects of rising inflation on the probability of default and credit losses of the financial sector of Iran's economy were greater than its positive effects, and increasing inflation in a three-quarter scenario led to increased credit losses.

According to the results, reduction of interest rates and expansionary monetary policy are the main causes of credit losses and default in Iran's economy. In such circumstances, banks provide more facilities and may even facilitate loan requirements, which leads to the provision of facilities to lower quality clients, and consequently, the default rate increases. From this aspect, the issue of lack of proper management in conceding credits in periods of interest rate reduction and expansionary monetary policy is the main determining factor in increasing the probability of default in the financial sector of Iran's economy.

On the other hand, the lending behavior of banks and financial institutions also changes based on the country's economic situation. For example, in the case of economic stability, banks expect investment projects to be profitable and efficient and investors to be able to repay their loans. Cessation of production and declining economic growth and consequently investment reduce the need for loans and credits and cause economic activities to decrease. In such a situation, troubled investors may go bankrupt and not be able to repay their debts, so their problem is transferred to the banks. In other words, investors finance their investment projects through bank credits by evaluating investment plans and considering profitable horizons. However, suppose there is a sudden change in economic conditions, or macroeconomic policies are made in such a way to disrupt the profitability of investors' projects. In that case, they will have difficulty repaying their loans, so that bank receivables will be delayed. The present study results indicate that the recession conditions have had the least possible effect on the probability of default of the country's banks. So either the banking system has not provided credit to the country's production sector and, accordingly, changes in production have had the least possible effect on the financial sector's credit losses. Or banks and credit institutions have considered the country's conditions of prosperity and recession to pay banking facilities and assess the probability of default of applicants who have taken loans.

In the studies on stress testing, the autoregressive (AR) method has been applied for examining the relationships between macroeconomic variables. This study investigates different economic sectors separately; these relationships are estimated by implementing the panel VAR model. 


\section{Reference}

Abdolshah, F. \& Moshiri, S. (2017). Stress Test of Default Probabilities of Iranian Banking Industry with Credit Portfolio Approach. Quarterly Journal of Economic Research, 17(66), 23-54.

Boss, M. (2002). A Macroeconomic Credit Risk Model for Stress Testing the Austrian Credit Portfolio. Financial Stability Report, 4, 64-82.

Buncic, D., \& Melecky, M. (2013). Macroprudential Stress testing of Credit Risk: A Practical Approach for policymakers. Journal of Financial Stability, 9(3), 347-370.

Fainstein, G., \& Novikov, I. (2011). The Comparative Analysis of Credit Risk

Determinants in the Banking Sector of the Baltic States. Review of Economics \& Finance, 1(3), 20-45.

Guerrieri, L., \& Welch, M. (2012). Can Macro Variables Used in Stress Testing Forecast the Performance of Banks?, Board of Governors of the Federal Reserve System (US), No.49.

Jahangard, E., \& Abdolshah, F. (2017). The Effect of Macroeconomic Variables on the Stability of Iranian Banks, Journal of Economic Policy Research, 9(18).

Jokivuolle, E., Virolainen, K., \& Vähämaa, O. (2008). Macro-model-based Stress testing of Basel II Capital Requirements. Bank of Finland Research Discussion Paper, (17).

Kafaie, M., \& Rahzani, M. (2017). Investigating the Effect of Macroeconomic Variables on the Liquidity Risk of Iranian Banks. Quarterly Journal of Economic Research and Policy. 25(81), 261-310.

Kraft, E., \& Jankov, L. (2005). Does Speed Kill? Lending Booms and their Consequences in Croatia. Journal of Banking \& Finance, 29(1), 105-121. 
Lindgren, C. J., Garcia, G., \& Saal, M. I. (1996). Bank Soundness and Macroeconomic Policy. International Monetary Fund.

Lu, W., \& Yang, Z. (2012). Stress Testing of Commercial Banks' Exposure to Credit Risk: A Study Based on Write-off Nonperforming Loans. Asian Social Science, 8(10), 16.

Melecky, M., \& Padpiera, A. M. (2012). Macroprudential Stress-testing Practices of Central Banks in Central and Southeastern Europe: An Overview and Challenges Ahead. World Bank Policy Research Working Paper, (5434).

Merton, R. C. (1974). On the Pricing of Corporate Debt: The Risk Structure of Interest Rates. The Journal of Finance, 29(2), 449-470.

Mohammed, F. A., \& Onour, I. (2019). Stress testing for credit risk exposure in Islamic banks. Management and Economics Research Journal, 6(2).

Misina, M., Tessier, D., \& Dey, S. (2006). Stress Testing the Corporate Loans Portfolio of the Canadian Banking Sector, Bank of Canada, No. 47.

Noroozi, P. (2014). The Effect of Macro Variables on Banks' Credit Risk in Iran. Quarterly Journal of Monetary-Banking Research, 7(20), 237-257.

Shijaku, H., \& Ceca, K. (2010). A Model for the Credit Risk in Albania Using Bank's Panel Data. Economic Policies in See: Design, Performance and Challenges, 53.

Sorge, M., \& Virolainen, K. (2006). A Comparative Analysis of Macro Stresstesting Methodologies with Application to Finland. Journal of financial stability, 2(2), 113-151.

Vazquez, F., Tabak, B. M., \& Souto, M. (2012). A Macro Stress Test Model of Credit Risk for the Brazilian Banking Sector. Journal of Financial Stability, 8(2), 69-83. 
Virolainen, K. (2004). Macro Stress Testing with a Macroeconomic Credit risk Model for Finland. Bank of Finland Research Discussion Paper, (18). Wilson, T C (1997a). Portfolio Credit Risk I. Risk, 10(9), 111-117.

Wilson, T C (1997b). Portfolio Credit Risk II. Risk 10(10), 56-61. 